\title{
HIF $2 \alpha$ reduces growth rate but promotes angiogenesis in a mouse model of neuroblastoma
}

\author{
Judith Favier*1,2,3, Stéphanie Lapointe ${ }^{1,2}$, Ricardo Maliba1,2 and \\ Martin G Sirois 1,2
}

Address: ${ }^{1}$ Research Center, Montreal Heart Institute, Montreal, Québec, Canada, ${ }^{2}$ Department of Pharmacology, Université de Montréal, Montreal, Québec, Canada and ${ }^{3}$ INSERM U772, Collège de France, Paris, France

Email: Judith Favier* - judith.favier@college-de-france.fr; Stéphanie Lapointe - stephalanie@hotmail.com;

Ricardo Maliba - ricardo_maliba@hotmail.com; Martin G Sirois - martin.sirois@icm-mhi.org

* Corresponding author

Published: 26 July 2007

BMC Cancer 2007, 7:139 doi:10.1 186/147|-2407-7-139

This article is available from: http://www.biomedcentral.com/147/-2407/7//39

(C) 2007 Favier et al; licensee BioMed Central Ltd.

This is an Open Access article distributed under the terms of the Creative Commons Attribution License (http://creativecommons.org/licenses/by/2.0), which permits unrestricted use, distribution, and reproduction in any medium, provided the original work is properly cited.
Received: 4 April 2007

Accepted: 26 July 2007

\begin{abstract}
Background: HIF2 $\alpha$ /EPASI is a hypoxia-inducible transcription factor involved in catecholamine homeostasis, vascular remodelling, physiological angiogenesis and adipogenesis. It is overexpressed in many cancerous tissues, but its exact role in tumour progression remains to be clarified.

Methods: In order to better establish its function in tumourigenesis and tumour angiogenesis, we have stably transfected mouse neuroblastoma NIE-I I 5 cells with the native form of HIF $2 \alpha$ or with its dominant negative mutant, HIF2 $\alpha(\mathrm{I}-485)$ and studied their phenotype in vitro and in vivo.

Results: In vitro studies reveal that HIF2 $\alpha$ induces neuroblastoma cells hypertrophy and decreases their proliferation rate, while its inactivation by the HIF $2 \alpha(I-485)$ mutant leads to a reduced cell size, associated with an accelerated proliferation. However, our in vivo experiments show that subcutaneous injection of cells overexpressing HIF $2 \alpha$ into syngenic mice, leads to the formation of tumour nodules that grow slower than controls, but that are well structured and highly vascularized. In contrast, HIF2 $\alpha$ (I-485)-expressing neuroblastomas grow fast, but are poorly vascularized and quickly tend to extended necrosis.
\end{abstract}

Conclusion: Together, our data reveal an unexpected combination between an antiproliferative and a pro-angiogenic function of HIF $2 \alpha$ that actually seems to be favourable to the establishment of neuroblastomas in vivo.

\section{Background}

Cellular responses to low oxygen tension are mainly mediated by the activation of heterodimeric transcription factors, called hypoxia inducible factors (HIFs), which consist of a constitutively expressed subunit (ARNT) and an oxygen-regulated subunit, mainly HIF $1 \alpha$ and HIF2 $\alpha$ (or EPAS1). Under normoxia, HIF $\alpha$ are subjected to enzymatic proline hydroxylation that target them for proteas- ome degradation via the von Hippel-Lindau (VHL) ubiquitin E3 ligase complex (for review, see [1]).

Both HIFs are overexpressed in many cancer cells and mainly associated with invasiveness, poor prognosis and/ or tumour angiogenesis (for review, see [2]). Experimental studies have however led to discrepant results regarding their role in cancer, pointing to functions varying depend- 
ing on the cell type. Experiments performed with HIF1 $\alpha-/$ - embryonic stem (ES) cells conflictingly revealed that HIF1 may act as a positive regulator of tumour growth, most likely through its activation of vascular endothelial growth factor (VEGF) expression [3] or as a negative regulator, possibly through the stabilization of p53 in hypoxic cells [4]. In pancreatic cancer, disruption of HIF1 pathway using a dominant negative strategy reduces tumourigenesis [5]. Opposite results have also been obtained concerning HIF2 $\alpha$. In renal carcinoma cells originating from patients affected by Von Hippel Lindau disease, the abnormal stabilization of HIF2 $\alpha$ appears to be directly responsible for tumourigenesis $[6,7]$. In teratomas derived from ES cells carrying an HIF2 $\alpha$ knock-in at the HIF1 $\alpha$ locus, Covello et al recently observed an increase in both vascular density and proliferation [8]. In contrast, transfection of HIF2 $\alpha$ in a breast cancer cell line inhibits tumour growth, both in vitro and in vivo [9], while it was recently demonstrated to display pro-apoptotic activities in both rat gliomas and ES cells-derived teratomas [10].

Neuroblastomas are highly vascularized tumours that constitute one of the most frequent solid malignancy of childhood. They arise from immature cells derived from the neural crest and are particularly sensitive to low oxygen tension. Hypoxic treatment of neuroblastoma cells leads to their dedifferentiation towards a neural crest phenotype [11], while overexpression of VHL leads to their differentiation into functional neuron-like cells [12]. Moreover, hypoxia was associated with an increased invasiveness of these tumours in vivo [11]. These data point to a role of the HIF pathway in the induction of neuroblastoma's tumour phenotype.

HIF2 $\alpha$ plays an important role in the sympathetic nervous system (SNS), both during embryogenesis [13] and in pathological conditions where it is associated with pheochromocytoma malignancy [14]. Hence, it appeared pertinent to assess its role in the SNS-derived model of neuroblastoma $\mathrm{C} 1300$. We thus carried out stable transfection of these cells with HIF2 $\alpha$ cDNA or with its dominant negative mutant HIF2 $\alpha(1-485)$ and show that HIF2 $\alpha$ displays antiproliferative but pro-angiogenic activities that favour the establishment of neuroblastoma nodules in vivo.

\section{Methods}

\section{Vector constructions}

pCDNA3.1-EPAS1 vector, encoding human HIF2 $\alpha$ cDNA (1-870) was a gift from S. McKnight. HIF2 $\alpha$ (1-485) cDNA was amplified from pCNDA3.1-EPAS1 plasmid using the elongase polymerase with the following primers: forward, 5'-GCCTCGAGCGACAATGACAGCTGACAAGGAGAAGAAAAGG-3' and reverse, 5'GCGGATCCTAGCTATTGGGCGTGGAGCAGCTGCT-
GCT-3', and cloned into PCRII-TOPO (Invitrogen). HIF2 $\alpha$ (1-485) cDNA fragment was then recovered by HindIII-XbaI digestion and subcloned into pCDNA3.1 vector (Invitrogen).

\section{Cell culture and stable transfections}

Murine adherent neuroblastoma C1300 cells (clone N1E115, a gift from N. Lamandé, INSERM U36/U833, Paris, France) were grown in $10 \mathrm{~cm}$ petri dishes in DMEM containing $4.5 \mathrm{~g} / \mathrm{L}$ glucose (Invitrogen) supplemented with $10 \%$ foetal bovine serum (Hyclone) and 2\% antibiotics; penicillin and streptomycin (Invitrogen). N1E-115 cells were transfected using Lipofectin transfection reagent (Invitrogen), as described by the manufacturer. Transfected cells were selected with G-418 $(750 \mu \mathrm{g} / \mathrm{ml}$; Geneticin; Invitrogen) and cloned by a limiting dilution method.

\section{RT-PCR}

Total RNAs were isolated using the RNeasy extraction kit (Qiagen) and reverse transcribed using random hexamers and the MMLV reverse transcriptase (Invitrogen) as described by the manufacturer. PCR reactions were performed as follows: cDNAs were denatured $\left(94^{\circ} \mathrm{C}\right.$ for 5 min), submitted to 30 cycles of amplification $\left(94^{\circ} \mathrm{C}\right.$ for 1 min, $\mathrm{Tm}^{\circ} \mathrm{C}$ for $1 \mathrm{~min}$ and $72^{\circ} \mathrm{C}$ for $1 \mathrm{~min}$ ) and to a final elongation $\left(72^{\circ} \mathrm{C}\right.$ for $\left.10 \mathrm{~min}\right)$. Primer sequences and $\mathrm{Tm}$ used are available upon request.

\section{Proteins assays}

Cells were lysed in Laemmli buffer and 25 to $100 \mu \mathrm{g}$ of proteins used for Western blot analyses. PVDF membranes were probed with a rabbit polyclonal anti-Tyrosine hydroxylase (1:1000; Institut Jacques Bois), a rabbit polyclonal anti-HIF1 $\alpha$ (1:3000, a generous gift from Dr. Darren Richard), anti-phospho-specific Akt IgG (1:1000), anti-phospho-p70 S6 Kinase (Thr389) IgG (1:1000; Cell Signaling Technology) or anti-p42/44 MAPK IgG (1:1000; New England Biolabs). Membranes were subsequently stripped in $\mathrm{NaOH}$ and probed with anti-Akt IgG (1:1000, Cell Signaling Technology) and anti-p70 S6 kinase IgG (1:200, sc-230; Santa Cruz). Immunoreactive bands were visualized by enhanced chemiluminescence, digitized using a 2-dimensional gel scanner, and quantified using Quantity One software (Bio-Rad). For HIF2 $\alpha$ western blot, proteins were extracted using the NE-PER Nuclear and Cytoplasmic Extraction Reagents (Pierce). $75 \mu \mathrm{g}$ of nuclear extracts were blotted on PVDF membranes and probed with the ep190b anti-human HIF2 $\alpha$ antibody (1:500; abcam).

In another set of experiments, the release of VEGF by native and transfected N1E-115 cells under normoxia and reduced oxygen tension was measured using the murine 
VEGF development ELISA kit (PeproTech) according to the manufacturer's instruction.

\section{Cell size evaluation}

Cell diameter was evaluated using the Adobe Photoshop software. In vitro, cells were seeded at low confluence in 10 $\mathrm{cm}$ Petri dishes, in order to avoid the formation of cell aggregates, and grown as described above. For each clone, 10 pictures were taken using a Sony Exwave HAD video camera connected to an Olympus CK2 microscope. In each field, 5 cells were randomly selected and their diameter was measured. This study was repeated once, for a total of 100 cells measured for each clone. For the in vivo measurements, the diameter of cells was measured on histological pictures of tissue sections stained with Masson's Trichrome (see Histology and immunohistochemistry section). For each clone, 15 cells form 3 different nodules were analysed, for a total of 50 cells per clone.

\section{In vitro proliferation assay}

500000 cells were seeded in $10 \mathrm{~cm}$ Petri dishes. After few hours, medium was replaced and the number of surviving cells $(T=0)$ evaluated by using a Coulter counter (Beckman Coulter). Further counting was performed after 72 , 96,120 and $144 \mathrm{~h}$. The relative proliferation rate of each clone was assessed by calculating the slope of each proliferation curve. This study was performed four times within few weeks of interval.

\section{In vivo tumourigenesis assay}

Sixty five 8 weeks-old, female A/J mice, were purchased from Jackson Laboratory and bred under standard conditions at the Experimental Animal Center of our Research center. Tumours were established in accordance to the guidelines set by the Montreal Heart Institute (MHI) animal care committee and the Canadian Council for Animal Protection. Each mouse was submitted to one injection of $2 \times 10^{6}$ cells in $500 \mu \mathrm{l}$ Matrigel (Becton Dickinson). Injections were performed subcutaneously at one site on the back of the mouse. The growth of tumour nodules was then measured bidirectionally every 2 days and tumour volume was calculated by the formula $\pi / 6$ length $^{2} \times$ width. Mice were sacrificed 4 weeks after inoculation. For four HIF2 $\alpha$ expressing cells, the MHI ethical committee allowed us to pursue our study up to day 35 post-inoculation.

\section{Histology and immunohistochemistry}

Tumours were resected and fixed for $24 \mathrm{~h}$ at room temperature, either in formalin or, for CD31 immunohistochemistry (IHC), in IHC zinc fixative (BD Biosciences Pharmingen). Samples were then dehydrated and embedded in paraffin and six $\mu$ m-thick sections were submitted to Masson's trichrome staining. Briefly, after treating tissue sections with Bouin's solution to intensify the final coloration, nuclei were stained with Weigert's iron hematoxylin, and cytoplasm and muscle with Beibrich scarletacid fuchsin. After treatment with phosphotungstic and phosphomolybdic acid, collagen was demonstrated by staining with aniline blue [15].

Immunohistochemistry was performed as previously described [16] with a rat anti-mouse CD31 (PECAM-1) monoclonal IgG (MEC13.3, BD Biosciences Pharmingen), a rabbit polyclonal anti-proliferating cell nuclear antigen (PCNA) IgG (FL-261, Santa Cruz Biotechnology), or an anti-cleaved caspase-3 (Cell signaling technology).

\section{Determination of tumour vessel density}

The number of blood vessels was quantified on Masson's trichrome stained sections. For each sample, the number of blood vessels was counted in 7 fields of $385 \mu \mathrm{m}^{2}$ each, in a blinded manner.

\section{Statistical analyses}

Statistical analyses were performed using the InStat ${ }^{\circledast}$ software. Differences in cell size were evaluated by unpaired t-test and variations in cell proliferation by a paired t-test. In vivo growth of tumours and vascular density differences were assessed by a Mann-Whitney test. A p value $<0.05$ was considered significant.

\section{Results}

Establishment and characterization of the cellular models We studied HIF2 $\alpha$ 's function in the mouse model of neuroblastoma C1300 (N1E-115 clone). To better characterize these cells, we performed RT-PCR experiments to seek for the expression of genes of interest (Fig. 1a). We observed that N1E-115 cells express both HIF1 $\alpha$ and HIF2 $\alpha$, their common target genes VEGF and adrenomedullin as well as several neuroblastoma classical markers including neuropilin-1, neuronal-specific enolase, Id2 and chromogranin $\mathrm{A}$.

We then stably transfected N1E-115 cells with plasmids encoding human HIF $2 \alpha$ or its dominant negative mutant (DN). HIF2 $\alpha$ DN (namely HIF $2 \alpha(1-485)$ ) comprises the DNA binding domain and the HLH-PAS dimerization domains, but lacks both transactivation domains (Fig. 1b). All commercially available anti-HIF2 $\alpha$ antibodies target the C-terminus of the protein, which happens to be deleted in HIF2 $\alpha(1-485)$. Screening for transfectants was thus performed by RT-PCR using primers specific to the human HIF2 $\alpha$ sequence (Fig. 1c, upper panel). To avoid unspecific responses due to clonal selection, we selected two clones expressing HIF2 $\alpha$ (E1 and E2) and two clones expressing HIF2 $\alpha(1-485)$ (DN5 and DN8). Western blot experiments using a specific anti-human HIF2 $\alpha$ antibody confirmed the nuclear expression of the transfected construct in HIF2 $\alpha$ clones (Fig. 1c, lower panel). Untrans- 

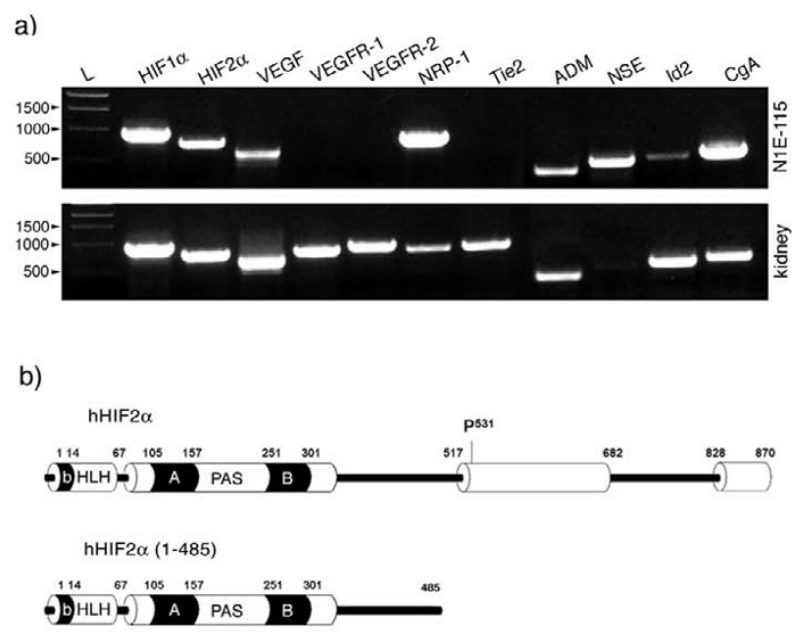

c)
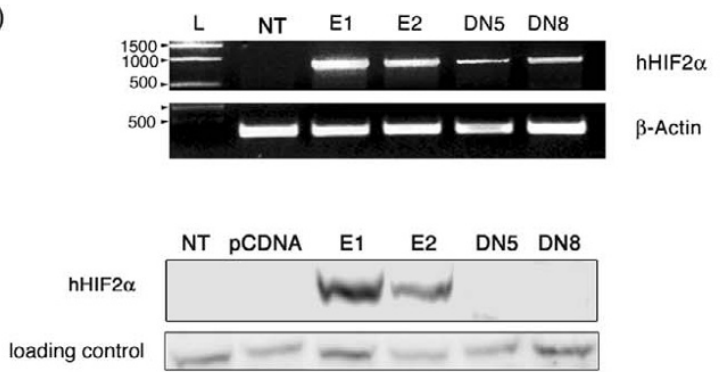

d)
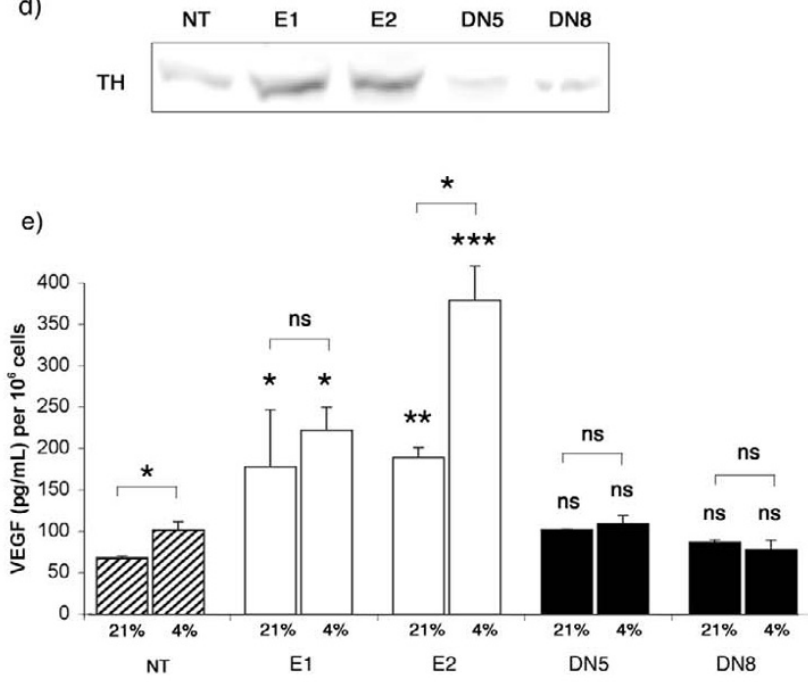

f)

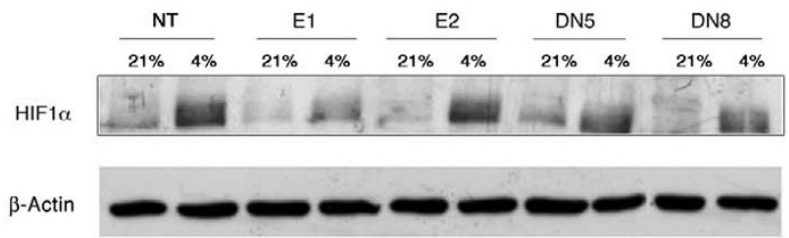

\section{Figure I}

Characterization of native and transfected NIE-I I 5 cells. a) Expression of HIFI $\alpha$, HIF2 $\alpha$, VEGF, Neuropilin-I (NRPI), adrenomedullin (ADM), neuronal-specific enolase (NSE), Id2 and Chromogranin A (CgA) as well as HIF2 $\alpha$ endothelial-specific targets VEGFR-I, VEGFR-2 and Tie2 in NIE-I I 5 cells and mouse kidney cDNAs. DNA ladder (L) is indicated in base pairs. b) Comparison of the human HIF2 $\alpha$ (hHIF2 $\alpha$ ) 870 amino acids protein with the HIF2 $\alpha($ I -485$)$ mutant shows that both activation domains have been truncated in the dominant negative form. c) Specific RT-PCR amplification of hHIF2 $\alpha$ sequence was used to confirm the efficiency of transfection with both hHIF2 $\alpha$ (EI and E2) and hHIF2 $\alpha($ I -485$)$ (DN5 and DN8) expressing vectors. Western blot using a specific anti-human HIF2 $\alpha$ antibody confirmed the nuclear presence of the wild-type protein in EI and E2 clones. d) Tyrosine hydroxylase (TH) expression was assessed by western blot and e) VEGF protein expression quantified by ELISA in duplicate $21 \%$ or $4 \% \mathrm{O}_{2}$ atmosphere. Asterisks on bars illustrate statistical significance compared to NT cells in the same oxygen condition. Upper asterisks indicate significance between $21 \%$ and $4 \% \mathrm{O}_{2}$ for each clone. f) Western blot evaluation of HIFI $\alpha$ levels revealed no variation between the different cell clones in both $21 \%$ and $4 \% \mathrm{O}_{2}$.

fected cells (NT) or cells transfected with the empty pCDNA3.1 vector were used as controls (C).

To confirm the activity of HIF $2 \alpha$ and HIF $2 \alpha(1-485)$ exogenous proteins, we studied the expression of tyrosine hydroxylase (TH), a known HIF2 $\alpha$ target gene in the sympathetic nervous system [17]. We observed an increase in TH protein expression in HIF $2 \alpha$ clones, and a reduction in HIF2 $\alpha(1-485)$ compared to control cells (Fig. 1d). We next incubated the cells in normoxia $\left(21 \% \mathrm{O}_{2}\right)$ or in low oxygen tension $\left(4 \% \mathrm{O}_{2}\right)$ for $6 \mathrm{~h}$ and evaluated the release of VEGF by ELISA (Fig. 1e). In controls cells, we confirmed that VEGF expression was indeed induced, although mod- erately, in response to decreased oxygen tension $(\mathrm{p}=$ $0,04)$. As expected, we noted a marked increase in VEGF levels in both E1 and E2 clones, in normoxia (161\% ( $\mathrm{p}=$ $0,017)$ and $178 \%(\mathrm{p}=0,012)$ increase respectively as compared to control cells) and in $4 \% \mathrm{O}_{2}(117 \%$ ( $\mathrm{p}=$ $0,004)$ and $272 \%(\mathrm{p}<0,001)$ increase respectively). In contrast, VEGF protein concentration was not modified in DN5 and DN8 clones in normoxia compared to control cells, while its hypoxic induction was repressed in both clones. Western blot evaluation of HIF1 $\alpha$ protein levels confirmed that the differences observed were not due to a deregulation of HIF1 $\alpha$ protein expression, but attributable to HIF $2 \alpha$ transfections (Fig. 1f). 


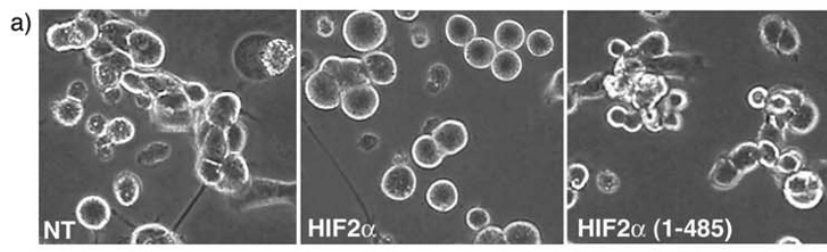

b)

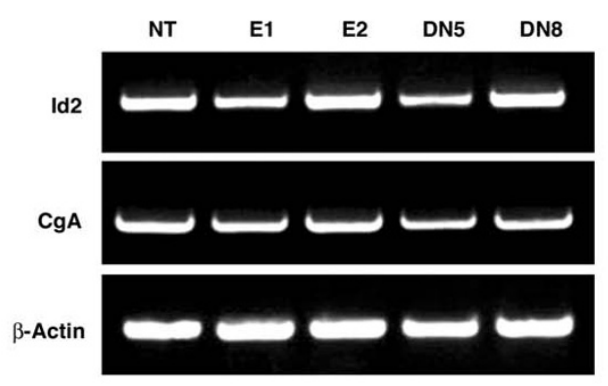

c)

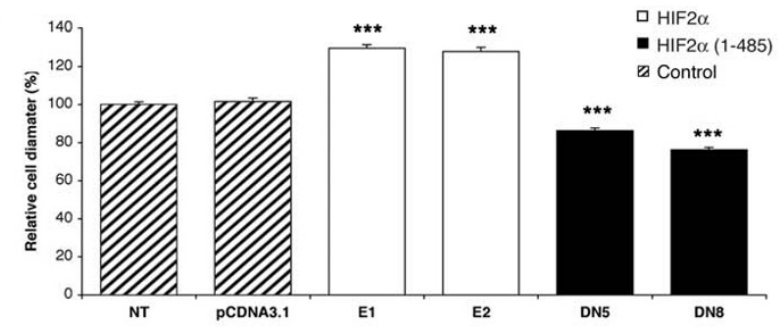

d)

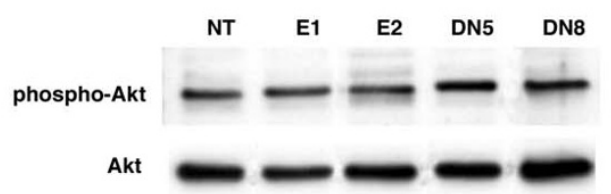

Figure 2

HIF $2 \alpha$ induces neuroblastoma cell hypertrophy. a) Morphology of control NIE-I I5 (NT), and NIE-I I 5 transfected with HIF2 $\alpha$ and HIF2 $\alpha(I-485)$ vectors. b) RT-PCR analyses of neural crest differentiation markers (Id2 and $\mathrm{CgA}$ c) Quantification of the average cell diameter of each clone. Cell size data are mean \pm SEM of 100 values for each clone, reported to $100 \%$ for NT cells. d) The difference in cell size was not attributable to modification in neither Akt protein expression nor phosphorylation as revealed by Western blot performed on protein extracted from the different clones.

\section{Effect of HIF2 $\alpha$ on neuroblastoma cell phenotype}

Hypoxia induces an immature phenotype of neuroblastoma cells [11], while inhibition of the HIF pathway by VHL overexpression mediates differentiation toward a neuron-like morphology [12]. We searched for such modifications in HIF2 $\alpha$ and HIF $2 \alpha(1-485)$ clones, but could not detect any change in the typical cell shape nor in the number of neuronal extension (Fig. 2a). To confirm this observation, we studied the expression of Id2 and CgA markers, which are respectively induced and downregulated during hypoxia-mediated neuroblastoma dedifferentiation $[11,18]$. Such RT-PCR analyses revealed the absence of any noticeable difference in their expression between the various clones (Fig. 2b).

Unexpectedly, we observed a marked modification in N1E-115 cell size (Fig. 2a and 2c): both HIF2 $\alpha$ clones displayed an average 30\% increase in cell diameter ( $\mathrm{p}<$ $0.001)$, while HIF $2 \alpha(1-485)$ cells were 15 to $25 \%$ smaller than native or pCDNA3.1-transfected cells ( $\mathrm{p}<0.001)$. We performed Western blot experiments to detect the expression and the phosphorylation of two protein kinases, known to play a role in the modulation of cell size [19], i.e. Akt (Fig. 2c) and p70 s6 kinase (data not shown). In both cases, there was no significant difference, neither in protein expression nor in phosphorylation between the various clones.

It is worth noting that such observations were also performed on histological sections of tumour nodules grown in vivo (see following experiments and Fig. 5) where we measured a $22 \%$ increase in cell diameter in HIF2 $\alpha$ and a $19 \%$ decrease in HIF2 $\alpha(1-485)$ nodules compared to control ones $(\mathrm{p}<0,001)$.

\section{HIF2 $\alpha$ reduces neuroblastoma cell growth in vitro}

The other major change in cell phenotype observed was a modification of proliferation (Fig. 3a). We indeed observed a 44 and 51\% decrease in the growth rate of HIF2 $\alpha$ cells in E1 $(\mathrm{p}=0.015)$ and E2 $(\mathrm{p}=0.004)$ clones, respectively, while cells expressing HIF $\alpha(1-485)$ grew 44 and $65 \%$ faster than controls in DN5 $(\mathrm{p}=0.048)$ and DN8 ( $p=0.039$ ) clones, respectively. During these experiments, we observed no increase in cell death in HIF $2 \alpha$ cells compared to control or HIF $2 \alpha(1-485)$ clones. The differences in proliferation rates were associated with a decrease in p42/44 mitogen activated protein kinase (MAPK) phosphorylation in HIF2 $\alpha$ clones, while this pathway appeared activated in HIF $2 \alpha(1-485)$ cells compared to controls.

\section{Effect of HIF2 $\alpha$ on tumour growth in vivo}

We then evaluated the effect of HIF $2 \alpha$ overexpression or inactivation in vivo in a tumourigenesis assay in syngenic $\mathrm{A} / \mathrm{J}$ mice. Cells were injected subcutaneously and the 
a)

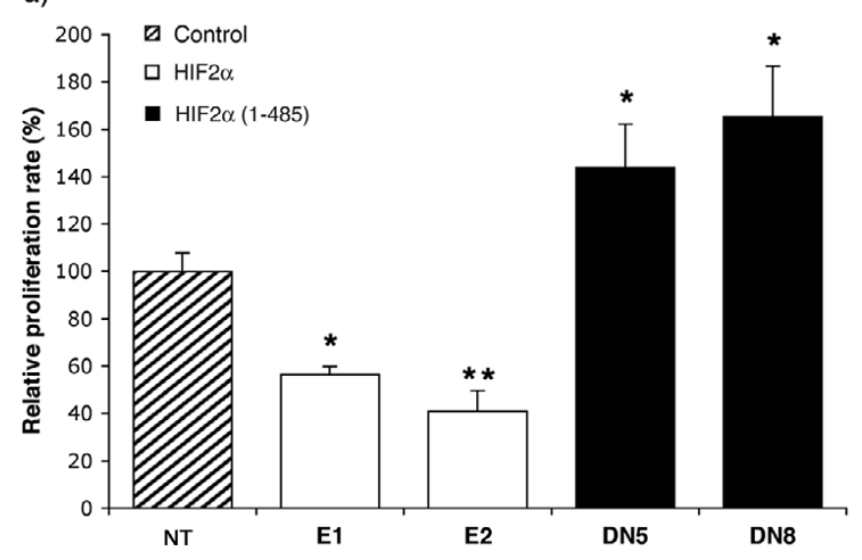

b)

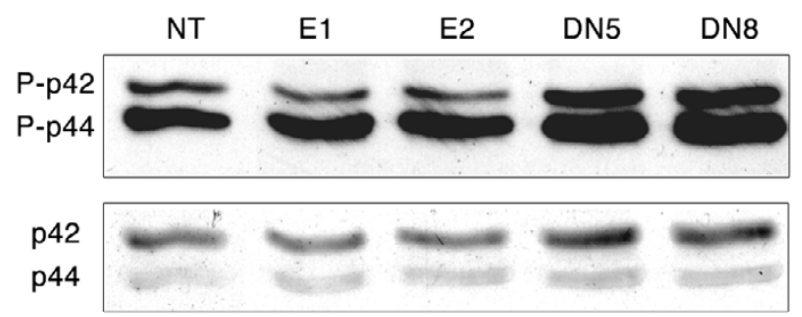

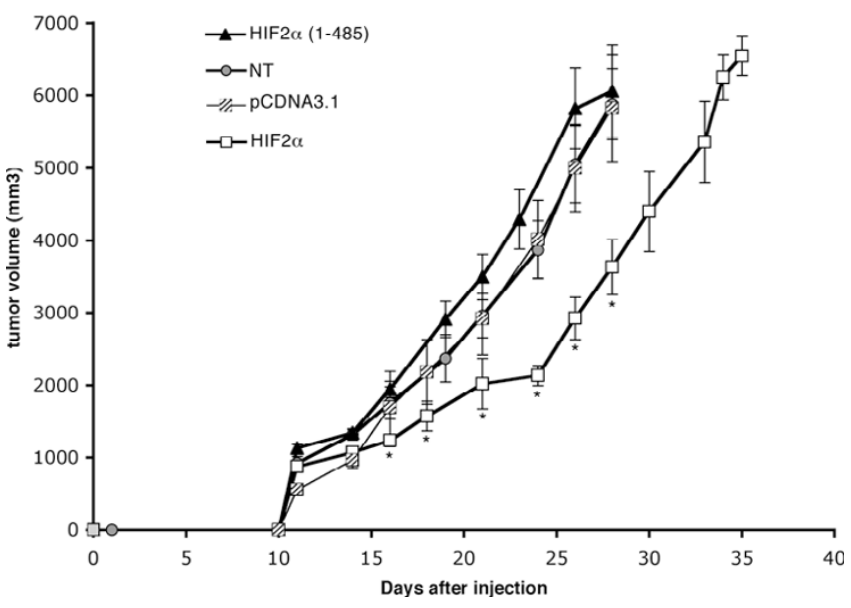

Figure 4

HIF $\alpha$ modulates the in vivo growth of neuroblastomas. The volume of tumour nodules was measured every 2 days after injection of control cells, HIF $2 \alpha$ or HIF2 $\alpha(I-485)$ transfected cells. Data are mean \pm SEM of 15 untransfected tumours (NT), 16 pCDNA3. I-transfected tumours, 18 HIF2 $\alpha$ tumours $(\mathrm{EI}(\mathrm{n}=9)$ and E2 $(\mathrm{n}=9))$, and I6 HIF2 $\alpha(\mathrm{I}-$ $485)$ tumours (DN5 $(n=9)$ and DN8 $(n=7))$. Each tumour corresponds to one injection in one mouse.

tumours ( $p=0.001)$. However, from day 24 onward, the growth curve of HIF $2 \alpha$ cells displayed a marked acceleration. We thus extended the evaluation period for four HIF $2 \alpha$ tumours. We observed that they reached the average size of 28-days control tumours 6 days after them, i.e. at day 34 .

Cells overexpressing HIF $2 \alpha(1-485)$ did not display the growth expected from the in vitro proliferation observations. First, they did grow slightly faster than control cells, to reach a maximal $22 \%$ volume increase at day $19(\mathrm{p}=$ 0.058). From day 19 onward, this divergence however diminished and at day 28, there was no distinction between control and HIF $2 \alpha(1-485)$ tumours volumes.

In an attempt to clarify this rather complex in vivo effect of HIF $2 \alpha$ on neuroblastoma growth, we removed tumours at days 19 (just before the growth acceleration of HIF $2 \alpha$ nodules) and 28 for controls and HIF $2 \alpha(1-485)$ cells and at days 19, 28 and 35 for HIF $2 \alpha$ nodules. Macroscopic examination revealed that 28-days HIF2 $\alpha(1-485)$ tumours were pale and highly necrotic compared to controls, whereas equivalent HIF $2 \alpha$ tumours (obtained at day 35) appeared particularly dense and red coloured (Fig. 5a). These observations were confirmed by histological observation of Masson's trichrome stained sections. Mas- cells when compared to controls. At day 24, the volume of HIF2 $\alpha$ nodules was $45 \%$ inferior to that of control 

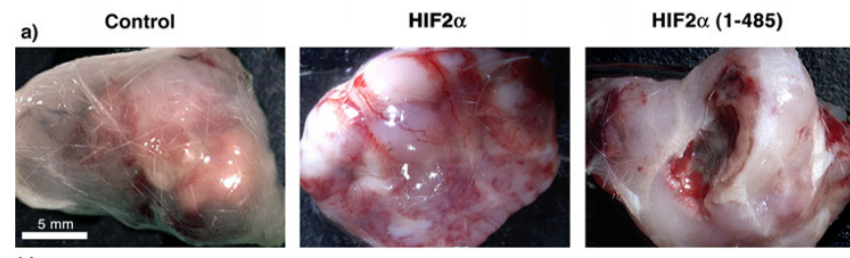

b)
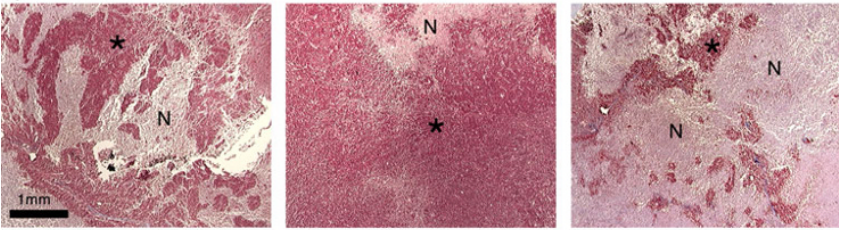

c)
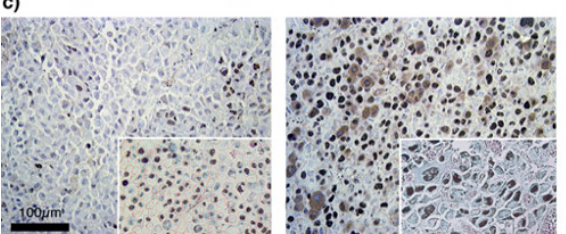

d)
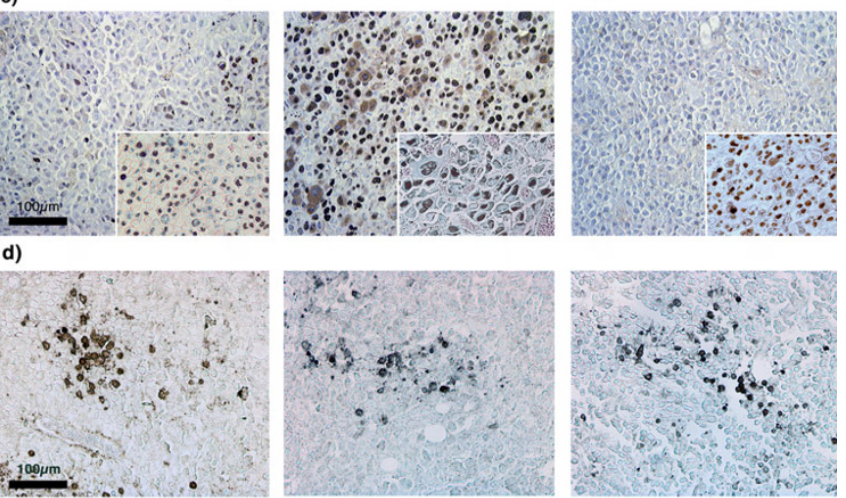

Figure 5

Effect of HIF2 $\alpha$ on tumour necrosis and late proliferation. a) Macroscopic observations of tumour nodules and b) histological analyses of Masson's trichrome stained sections reveal extended necrotic areas within day $28-\mathrm{HIF} 2 \alpha(\mathrm{I}-$ $485)$ expressing neuroblastomas, compared to control tumours. Such defects are less often observed up to day 35 in HIF2 $\alpha$ nodules. c) PCNA immunohistochemistry reveals, within non-necrotic regions (*), a significantly increased number of proliferating cells in HIF2 $\alpha$ tumours, while HIF2 $\alpha(I-485)$ neuroblastomas present very few labelled cells at day 28. There is no marked difference in proliferation between the three tumour types at day 19 (insets).

sive necrosis was observed in HIF2 $\alpha(1-485)$ tumours as compared to controls, while HIF $2 \alpha$ nodules presented a much-limited number of necrotic regions (Fig. 5b). At day 19 , cell proliferation revealed by proliferating cell nuclear antigen (PCNA) immunohistochemistry did not show any difference between the 3 tumour types, which were all actively proliferating (Fig. 5C insets). In contrast, at later stages, we observed that within healthy-looking areas of tumours, the number of proliferating cells was markedly increased in both 28- and 35-days HIF $2 \alpha$ nodules compared to controls. In contrast, there was almost no PCNA staining in cells expressing the HIF $2 \alpha$ DN (Fig. 5c). This observation does suggest that 28-day HIF2 $\alpha(1-485)$ tumours were most probably entering a regression process, while their equivalent 35 -day HIF $2 \alpha$ counterparts
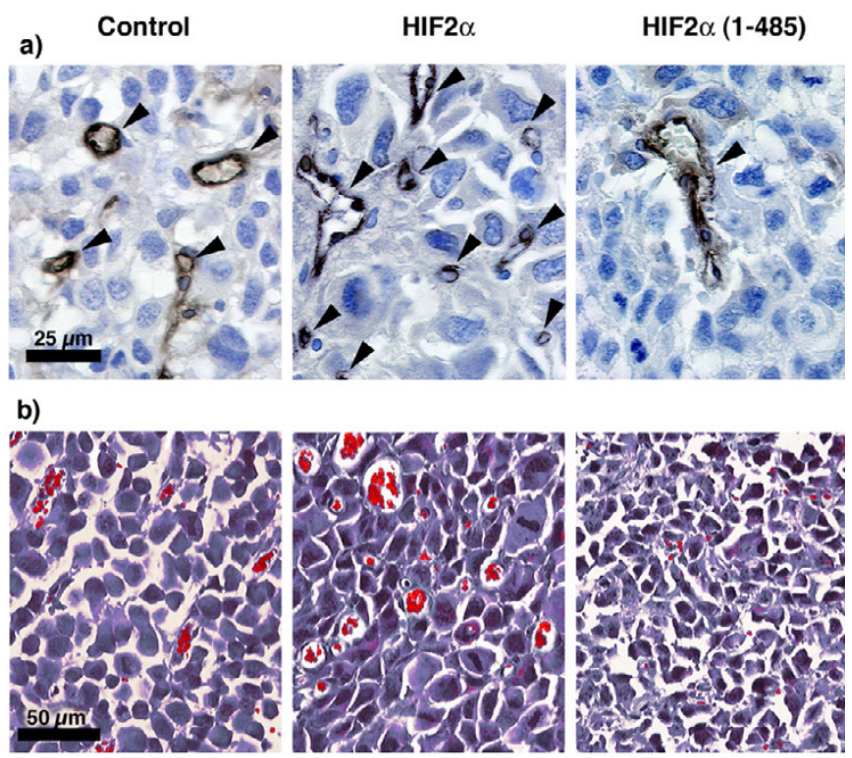

c)

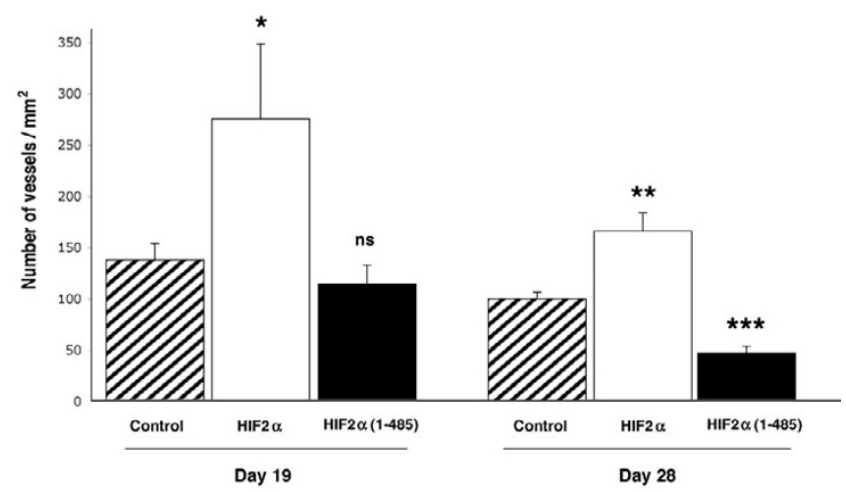

Figure 6

HIF $2 \alpha$ promotes neuroblastoma angiogenesis. a) Positive staining of endothelial cells in tumours was revealed by PECAM/CD3 I immunohistochemistry and b) by Masson's trichrome staining of tumour sections. Both revealed an increase in blood vessel density in HIF $2 \alpha$ tumours versus control ones, whereas the expression of the dominant negative HIF $2 \alpha(1-485)$ is associated with an apparent inhibition of the angiogenic process. c) Quantification of blood vessel density represents mean \pm SEM of $3 N T, 3$ HIF $2 \alpha$ and 4 HIF $2 \alpha(I-485)$ at day I9, and of I I NT, II HIF2 $\alpha$ and 6 HIF2 $\alpha(I-485)$ tumours and day 28.

were particularly proliferating. Finally, as HIFs have been described to induce or repress apoptosis, depending on the cell type, we studied the number of cleaved caspase- 3 positive cells, outside of the large necrotic areas. In all tumours studied we observed isolated apoptotic cells as well as several areas presenting an increased density of positive cells, but we were unable to use these criteria to discriminate between control, HIF2 $\alpha$ and HIF2 $\alpha(1-485)$ tumours (Fig. 5d). 


\section{HIF2 $\alpha$ promotes tumour angiogenesis in vivo}

We hypothesized that the delayed growth of HIF $2 \alpha$ tumours and the simultaneous necrosis of fast-growing HIF2 $\alpha(1-485)$ nodules could be respectively imputable to an increase and a defect in the angiogenic process. We performed immunohistochemistry analyses to detect the endothelial marker PECAM/CD31, which highlighted a marked reduction in the vascularization of HIF $2 \alpha(1-485)$ expressing tumours and an amplification of angiogenesis in HIF2 $\alpha$ ones (Fig. 6a). Quantification of blood vessels (Fig. 6c) within healthy regions of each tumour type revealed that vascular density was markedly increased in HIF2 $\alpha$ tumours compared to controls nodules (96\% increase at day $19, \mathrm{p}=0.05$, and $63 \%$ increase at day 28 , $\mathrm{p}=0.006)$. In contrast, although angiogenesis was comparable between HIF $2 \alpha(1-485)$ nodules and control ones at day 19 , it then diminished in HIF $2 \alpha(1-485)$ to reach a $54 \%$ decrease in the number of blood vessels compared to control tumours at day $28(\mathrm{p}=0.001)$.

\section{Discussion}

In the present study, we report that HIF $2 \alpha$ promotes neuroblastoma cell hypertrophy and reduces their proliferation in vitro. However, we also demonstrate that in vivo, its antiproliferation function acts in combination with an amplification of the angiogenic process to promote the establishment of well-structured neuroblastoma nodules.

To evaluate the role of HIF $2 \alpha$ in neuroblastoma, we overexpressed its native form or inactivated its function using a DN strategy. We used the well-characterized C-terminal deletion mutant HIF2 $\alpha(1-485)$, which forms a heterodimer with ARNT, binds to the hypoxia-responsive element (HRE) sequence but lacks the ability to transactivate HRE-driven transcription [20,21]. In light of the parameters studied, we observed reproducible and opposite effects of HIF $2 \alpha$ and HIF2 $\alpha(1-485)$ respectively, and equivalent results were obtained with two independent clones of each transfectant. These observations strongly argue for the efficiency and the specificity of this approach. However, it is worth noting that HIF2 $\alpha(1-485)$ may also prevent HIF1 $\alpha$-mediated transcription [21]. In our model, we thus cannot exclude that HIF2 $\alpha(1-485)$ effects may also be partly due to HIF1 $\alpha$ inhibition.

We observed a marked effect of HIF $2 \alpha$ on the modulation of cell size, which was quantified in vitro as well as on histological sections of tumour nodules. The impact of this observation is still unclear, and to the best of our knowledge, such an induction of neuroblastoma cell hypertrophy has never been reported. Interestingly, cellular hypertrophy has been associated with cell cycle arrest in mesangial or vascular smooth muscle cells $[22,23]$. HIF $2 \alpha$ enlarged cells also displayed a reduced proliferating rate associated with a diminution in p42/44 MAPK phospho- rylation, while proliferation and phospho-p42/44 were increased in small HIF2 $\alpha(1-485)$ cells. Although this is the first report of an antiproliferative role of HIF $2 \alpha$, similar activities of HIF $1 \alpha$ have already been described in several cells types $[4,24,25]$. Consequently, these in vitro data led us to conclude that HIF2 $\alpha$ would present antitumoral activities in neuroblastoma, as previously proposed in breast cancer cells [9] and gliomas [10]. Our in vivo observations led us to reconsider this initial assumption.

We indeed show that overexpression of HIF $2 \alpha$ leads to a delayed growth of neuroblastoma nodules, characterized by a well-organized structure and a homogeneous histology 5 weeks after inoculation. In contrast, despite an apparent acceleration in tumour growth, 4 week-old HIF2 $\alpha(1-485)$ neuroblastomas present extensive necrosis associated with a marked reduction in the number of proliferating cells within the apparently healthy tumour territories. Due to ethical restriction, we have not studied HIF2 $\alpha(1-485)$ tumours beyond this 28 -day period. The histological analysis of these tissues, together with the PCNA immunohistochemistry data, were however suggestive of a forthcoming regression, or at least growth arrest, of neuroblastomas expressing HIF $2 \alpha$ DN. Hence, the antiproliferative role of HIF $2 \alpha$ appears to allow the favourable formation of well-organized tumour nodules instead of reducing neuroblastoma tumourigenesis, as initially assumed. These findings confirm the complexity of HIF $2 \alpha$ activity in cancer, which appears to be highly variable depending on the cell-type. In gliomas, Acker et al. observed a comparable negative effect of HIF $2 \alpha$ on tumour growth, but an exact opposite phenotype on histology, with increased necrosis in HIF $2 \alpha$ tumours and the presence of micronecrotic areas in HIF2 $\alpha$-DN-expressing ones [10].

Finally, we observed that HIF2 $\alpha$ transfected cells led to the formation of particularly vascularized tumours. In contrast, we observed that there was a clear defect in the longterm angiogenic progression within neuroblastomas formed by HIF $2 \alpha(1-485)$ cells. These tumours were able to initiate a vascularization process, but after four weeks of growth, they presented a marked reduction in vascular density, which could be expected to be responsible for the growth arrest and the important necrosis we observed. The pro-angiogenic role of HIF $2 \alpha$ has been established in vivo during embryogenesis [26] and in a wound healing assay [27]. In pathological angiogenesis such a role has been suggested by a wealth of expression studies performed on tissue sections, but remained to be clarified in experimental tumour angiogenesis. Recently, discrepant results have been obtained in two models of ES-cellsderived teratomas, demonstrating a positive effect of HIF $2 \alpha$ on vascular density [8], or an increase in vessel diameter but no modification of blood vessel density 
[10]. Our results reveal a pro-angiogenic function of HIF2 $\alpha$ by increasing blood vessel density in neuroblastoma, probably mediated by VEGF overexpression. The long-term anti-angiogenic effect of HIF $2 \alpha(1-485)$ demonstrates that this transcription factor's endogenous activity is required for an optimal vascularization of such tumours, putatively by improving the integrity and maintenance of the vascular network. These data support a very recently published study, which reported that high HIF $2 \alpha$ protein levels were correlated with advanced clinical stage and high VEGF expression and predicted poor prognosis in a clinical neuroblastoma material [28].

\section{Conclusion}

In conclusion, this study confirms the cell-type-dependent heterogeneity of HIF $2 \alpha$ 's function in cancer and reveals its unexpected antiproliferative role in the N1E115 neuroblastoma cell line. Instead of inhibiting cancer progression, this function seems to act in combination with a pro-angiogenic activity of this transcription factor to favour the establishment of appropriately fed, well oxygenized, strong and thus potentially aggressive tumours. These complementary functions, acting together, thus emphasize a favourable role of HIF $2 \alpha$ in neuroblastoma tumourigenesis by providing sustained tumour growth, albeit at a slower rate.

\section{Competing interests}

The author(s) declare that they have no competing interests.

\section{Authors' contributions}

JF conceived the study, performed most experiments and wrote the manuscript. SL performed some western blot experiments and participated to cell culture studies. RM carried out the VEGF ELISA assay. MGS participated in the design and coordination of the study and helped to draft the manuscript. All authors read and approved the final manuscript.

\section{Acknowledgements}

We would like to thank Pr. Xavier Jeunemaitre for helpful discussion and critical reading of the manuscript. We thank Dr. D. Russell and Dr. S. McKnight for providing the original HIF2 $\alpha$ plasmid, Dr. N. Lamandé for NIE-I I 5 cells and Dr. D. Richard for the gift of anti-HIFI $\alpha$ antibody. We are also grateful to Dominique Lauzier for her excellent technical assistance and to Maya Mamarbachi and Dr. Angelo Calderone for their precious help and advise. Dr. Favier was recipient of a fellowship from the Fondation Simone et Cino del Duca and from the Fonds de la Recherche en Santé du Québec. Dr. Favier has been a recipient of a Foundation Bettencourt Schueller award and is now supported by the Collège de France.

\section{References}

I. Schofield CJ, Ratcliffe PJ: Oxygen sensing by HIF hydroxylases. Nat Rev Mol Cell Biol 2004, 5(5):343-354.

2. Hopfl G, Ogunshola O, Gassmann M: HIFs and tumors - causes and consequences. Am J Physiol Regul Integr Comp Physiol 2004, 286(4):R608-623.
3. Ryan HE, Lo J, Johnson RS: HIF-I alpha is required for solid tumor formation and embryonic vascularization. Embo J 1998, I7(II):3005-3015.

4. Carmeliet $P$, Dor $Y$, Herbert JM, Fukumura D, Brusselmans $K$, Dewerchin M, Neeman M, Bono F, Abramovitch R, Maxwell P, et al.: Role of HIF-I alpha in hypoxia-mediated apoptosis, cell proliferation and tumour angiogenesis. Nature 1998 394(6692):485-490.

5. Chen J, Zhao S, Nakada K, Kuge Y, Tamaki N, Okada F, Wang J, Shindo M, Higashino F, Takeda $K$, et al:: Dominant-negative hypoxia-inducible factor- $I$ alpha reduces tumorigenicity of pancreatic cancer cells through the suppression of glucose metabolism. Am J Pathol 2003, I62(4): |283-|29|.

6. Kondo K, KIco J, Nakamura E, Lechpammer M, Kaelin WG Jr: Inhibition of HIF is necessary for tumor suppression by the von Hippel-Lindau protein. Cancer Cell 2002, I (3):237-246.

7. Maranchie JK, Vasselli JR, Riss J, Bonifacino JS, Linehan WM, Klausner RD: The contribution of VHL substrate binding and HIFIalpha to the phenotype of VHL loss in renal cell carcinoma. Cancer Cell 2002, I(3):247-255.

8. Covello KL, Simon MC, Keith B: Targeted replacement of hypoxia-inducible factor-Ialpha by a hypoxia-inducible factor-2alpha knock-in allele promotes tumor growth. Cancer Res 2005, 65(6):2277-2286.

9. Blancher C, Moore JW, Talks KL, Houlbrook S, Harris AL: Relationship of hypoxia-inducible factor (HIF)- I alpha and HIF-2alpha expression to vascular endothelial growth factor induction and hypoxia survival in human breast cancer cell lines. Cancer Res 2000, 60(24):7106-7II3.

10. Acker T, Diez-Juan A, Aragones J, Tjwa M, Brusselmans K, Moons L, Fukumura D, Moreno-Murciano MP, Herbert JM, Burger A, et al.: Genetic evidence for a tumor suppressor role of HIF-2alpha. Cancer Cell 2005, 8(2):|3|-|4|.

II. Jogi A, Ora I, Nilsson H, Lindeheim A, Makino Y, Poellinger L, Axelson $H$, Pahlman S: Hypoxia alters gene expression in human neuroblastoma cells toward an immature and neural crest-like phenotype. Proc Natl Acad Sci USA 2002, 99( I 0):702I-7026.

12. Murata H, Tajima N, Nagashima Y, Yao M, Baba M, Goto M, Kawamoto S, Yamamoto I, Okuda K, Kanno H: Von Hippel-Lindau tumor suppressor protein transforms human neuroblastoma cells into functional neuron-like cells. Cancer Res 2002, 62(23):7004-70II.

13. Tian H, Hammer RE, Matsumoto AM, Russell DW, McKnight SL: The hypoxia-responsive transcription factor EPASI is essential for catecholamine homeostasis and protection against heart failure during embryonic development. Genes Dev 1998, I 2(2I):3320-3324.

14. Favier J, Plouin PF, Corvol P, Gasc JM: Angiogenesis and vascular architecture in pheochromocytomas : distinctive traits in malignant tumors. Am J Pathol 2002, I6 I (4): I235-I246.

15. Lillie R: Further experiments with the Masson trichrome modification of Mallory's connective tissue stain. Stain Technol 1940:15-17.

16. Marchand GS, Noiseux N, Tanguay JF, Sirois MG: Blockade of in vivo VEGF-mediated angiogenesis by antisense gene therapy: role of Flk-I and Flt-I receptors. Am J Physiol Heart Circ Physiol 2002, 282(I): $\mathrm{HI} 94-204$

17. Schnell PO, Ignacak ML, Bauer AL, Striet JB, Paulding WR, CzyzykKrzeska MF: Regulation of tyrosine hydroxylase promoter activity by the von Hippel-Lindau tumor suppressor protein and hypoxia-inducible transcription factors. J Neurochem 2003 , 85(2):483-49I

18. Lofstedt T, Jogi A, Sigvardsson M, Gradin K, Poellinger L, Pahlman S, Axelson $\mathrm{H}$ : Induction of ID2 expression by hypoxia-inducible factor- I: a role in dedifferentiation of hypoxic neuroblastoma cells. J Biol Chem 2004, 279(38):39223-3923I.

19. Kozma SC, Thomas G: Regulation of cell size in growth, development and human disease: PI3K, PKB and S6K. Bioessays 2002, 24(I):65-7I.

20. Maemura K, Hsieh CM, Jain MK, Fukumoto S, Layne MD, Liu Y, Kourembanas S, Yet SF, Perrella MA, Lee ME: Generation of a dominant-negative mutant of endothelial PAS domain protein I by deletion of a potent $\mathrm{C}$-terminal transactivation domain. Biol Chem 1999, 274(44):31565-31570. 
21. Shimba S, Wada T, Hara S, Tezuka M: EPASI promotes adipose differentiation in 3T3-LI cells. J Biol Chem 2004, 279(39):40946-40953.

22. Wolf G, Schroeder R, Zahner G, Stahl RA, Shankland SJ: High glucose-induced hypertrophy of mesangial cells requires p27(Kip I), an inhibitor of cyclin-dependent kinases. $\mathrm{Am} J$ Pathol 200I, I58(3): I09I-II00.

23. Owens GK, Geisterfer AA, Yang YW, Komoriya A: Transforming growth factor-beta-induced growth inhibition and cellular hypertrophy in cultured vascular smooth muscle cells. J Cell Biol 1988, 107(2):77I-780.

24. Goda N, Ryan HE, Khadivi B, McNulty W, Rickert RC, Johnson RS. Hypoxia-inducible factor Ialpha is essential for cell cycle arrest during hypoxia. Mol Cell Biol 2003, 23(I):359-369.

25. Koshiji M, Kageyama Y, Pete EA, Horikawa I, Barrett JC, Huang LE: HIF-I alpha induces cell cycle arrest by functionally counteracting Myc. Embo J 2004, 23(9):1949-1956.

26. Peng J, Zhang L, Drysdale L, Fong GH: The transcription factor EPAS-1/hypoxia-inducible factor 2alpha plays an important role in vascular remodeling. Proc Natl Acad Sci USA 2000, 97(15):8386-8391.

27. Takeda N, Maemura K, Imai Y, Harada T, Kawanami D, Nojiri T, Manabe I, Nagai R: Endothelial PAS domain protein I gene promotes angiogenesis through the transactivation of both vascular endothelial growth factor and its receptor, FIt-I. Circ Res 2004, 95(2): I 46-153.

28. Holmquist-Mengelbier L, Fredlund E, Lofstedt T, Noguera R, Navarro S, Nilsson H, Pietras A, Vallon-Christersson J, Borg A, Gradin K, et al.: Recruitment of HIF- Ialpha and HIF-2alpha to common target genes is differentially regulated in neuroblastoma: HIF2alpha promotes an aggressive phenotype. Cancer Cell 2006, I0(5):413-423.

\section{Pre-publication history}

The pre-publication history for this paper can be accessed here:

http://www.biomedcentral.com/1471-2407/7/139/pre pub

Publish with Biomed Central and every scientist can read your work free of charge

"BioMed Central will be the most significant development for disseminating the results of biomedical research in our lifetime. "

Sir Paul Nurse, Cancer Research UK

Your research papers will be:

- available free of charge to the entire biomedical community

- peer reviewed and published immediately upon acceptance

- cited in PubMed and archived on PubMed Central

- yours - you keep the copyright

Submit your manuscript here:

http://www.biomedcentral.com/info/publishing_adv.asp
BioMedcentral 